\title{
Sediment transport rate-based model for rainfall-induced soil erosion
}

\author{
Zhi-Qiang Deng ${ }^{a, *}$, João L.M.P. de Lima ${ }^{b}$, Hoon-Shin Jung ${ }^{a}$ \\ a Department of Civil and Environmental Engineering, Louisiana State University, Baton Rouge, LA 70803-6405, USA \\ b IMAR-Institute of Marine Research, Coimbra Interdisciplinary Centre, Department of Civil Engineering, Faculty of Science and Technology, \\ Campus II-University of Coimbra, 3030-788 Coimbra, Portugal
}

\section{A R T I C L E I N F O}

\section{Article history:}

Received 7 March 2008

Received in revised form 25 August 2008

Accepted 9 September 2008

\section{Keywords:}

Overland flow

Soil erosion

Sediment transport

Modelling

\begin{abstract}
A B S T R A C T
A one-dimensional mathematical model, termed sediment transport rate-based model, is developed for determining rainfall-induced soil erosion and sediment transport. The model is comprised of (1) the kinematic-wave equation for overland flow, (2) a transport rate-based advection equation for rainfallinduced soil erosion and sediment transport, and (3) a semi-Lagrangian algorithm for numerical solution of the soil erosion and sediment transport equation. A series of soil flume experiments under simulated rainfalls were conducted to simulate the overland flow and sediment transport and to test the sediment transport rate-based model. Numerical results of sediment transport rate-based model indicate that (i) hydrographs display an initial rising limb, followed by a constant discharge and then a recession limb; (ii) sediment transport rate graphs exhibit the distributions similar to the hydrographs; and (iii) sediment concentration graphs show a steep-receding limb followed by a constant distribution and a receding tail. The numerically simulated hydrographs, sediment transport rate and concentration distributions are in good agreement with those measured in laboratory experiments, demonstrating the efficacy of the transport rate-based model.

(c) 2008 Elsevier B.V. All rights reserved.
\end{abstract}

\section{Introduction}

Soil erosion has been recognized as a serious environmental and soil degradation problem. It can reduce soil productivity and increase sediment and other pollution loads in receiving waters. Estimation of soil erosion is therefore essential to issues of land and water management, including TMDL (Total Maximum Daily Load) calculations, BMP (Best Management Practice) implementation and evaluation, sediment transport and storage in lowlands, reservoirs, estuaries, and irrigation and hydropower systems.

Mathematical models have been proven to be a cost-effective tool for improving our understanding of erosion processes and evaluating possible effects of land use changes on soil erosion and water quality. A sound mathematical model can provide an efficient and economic tool by which a large number of scenarios can be simulated and compared in a short time and then the best alternative of addressing the problems may be found. Consequently, a wide spectrum of models, ranging from simple empirical formulas to comprehensive distributed descriptions (Woolhiser et al., 1990; Smith et al., 1995; Sander et al., 1996; Morgan et al., 1998; Parlange et al., 1999; Rose, 2001; Hairsine et al., 2002; Sander et al., 2002; Aksoy and Kavvas, 2005), has been proposed for the description and prediction of soil erosion and

\footnotetext{
* Corresponding author. Tel.: +1 225578 6850; fax: +1 2255788652. E-mail address: zdeng@lsu.edu (Z.-Q. Deng).
}

sediment transport. Some of the models show great promise and have been increasingly used (Singh and Woolhiser, 2002).

Sander et al. (1996) extended the model presented by Hairsine and Rose to account for the time variation of suspended sediment concentration during an erosion event and proposed a simple analytical solution for the extended model. Morgan et al. (1998) presented a dynamic distributed model, called EUROSEM (European Soil Erosion Model), for simulating sediment transport, erosion and deposition over the land surface by rill and interill processes in single storms for both individual fields and small catchments. Heilig et al. (2001) tested the development of a shield over the original soil and associated changes in sediment concentrations using the Rose model and a simple laboratory experiment. A common feature of the models is that the sediment concentration distributions simulated using the models have an initial sediment concentration of zero. This type of sediment concentration distributions was supported by some laboratory experiments, as shown in Figs. 3 and 4 of Heilig et al. (2001). However, most measured sediment concentration distributions approximately exhibit the first-flush phenomenon: a high initial sediment concentration followed by a gradual decline, as demonstrated in Fig. 1 (period 1) in Polyakov and Nearing (2003), Fig. 3 in Morgan et al. (1998), Fig. 1 in Rose and Hogarth (1998), and Figs. 1-3 in Sander et al. (1996). The experimental data collected by Polyakov and Nearing (2003) provides novel insights into sediment transport in rill flow under deposition and detachment conditions. Morgan et al. (1998) stressed that since, during a rainstorm, splash erosion will already be taking place when runoff begins, the initial sediment concentration in the runoff cannot be taken as zero. Woolhiser et al. 
(1990) made a similar comment on the initial sediment concentration. It is, therefore, essential to develop an alternative model that is able to simulate the soil erosion and sediment transport processes with a non-zero initial sediment concentration. Such a model may also facilitate the computation of sediment discharge.

Soil loss is commonly computed as a sediment discharge (also called sediment transport rate) to give a mass (or volume) of sediment passing a given point in a given time (Smith et al., 1995; Morgan et al., 1998; Folly et al., 1999; Veihe et al., 2001). Currently, the sediment discharge is calculated based on the product of the rate of runoff (flow discharge) and the simulated sediment concentration in the flow. Sediment discharges or sediment transport rates predicted using models with an initial sediment concentration of zero may result in erroneous load estimates for events of consequential length, especially when the length of sediment concentration rising period is comparable to that of concentration falling period, as shown in Fig. 3 in Morgan et al. (1998). It is therefore desirable to have a sediment discharge or transport rate-based model so that the sediment discharge can be directly solved from the model. Once the sediment discharge $C$ becomes available, sediment concentration $c$ can be easily determined from $c=C / Q$ because the prediction of discharge or hydrographs (relationship between the flow discharge $Q$ and time) is relatively easy and accurate.

The overall goal of this paper is therefore to develop a new sediment transport rate (sediment discharge)-based model for simulating rainfall-induced soil erosion and accompanying sediment transport process. The specific objectives are (i) to present a sediment transport rate-based mathematical model for the overland soil erosion based on the characteristics of rainfall-induced soil erosion; (ii) to propose an efficient method for numerical solution of the model equations; and (iii) to test the efficacy of the mathematical model using laboratory data. The three specific objectives are presented in the following three consecutive Sections $2-4$, respectively.

\section{Rainfall-induced soil erosion and sediment transport equations}

The rainfall-induced overland soil erosion and sediment transport are driven by rainfall and a non-uniform flow with an increasing discharge along the slope. It is therefore necessary and convenient to mathematically describe the overland flow and sediment transport process with two governing equations, although physically the flow and sediment erosion and transport are inseparable.

\subsection{Kinematic-wave overland flow equations}

Flow over a pervious steep plane is generally described by the kinematic-wave approximation of the Saint-Venant shallow-water equations, stating the laws of conservation of mass and momentum of the water flowing longitudinally and infiltrating vertically (Woolhiser, 1975; Martin and McCutcheon, 1999). The kinematic-wave equation can be expressed on a unit width and uniform slope basis as:

$\frac{\partial h}{\partial t}+\frac{\partial(u h)}{\partial x}=I-f$

with

$u=\alpha h^{m-1}$ or $Q_{\mathrm{f}}=\alpha W h^{m}$

where $h$ is the depth of overland flow $[\mathrm{L}], t$ is time $[\mathrm{T}], u$ is the velocity of the flow $\left[\mathrm{L} \mathrm{T}^{-1}\right], x$ is distance along the flow direction $[\mathrm{L}], I$ denotes the rainfall intensity $\left[\mathrm{L} \mathrm{T}^{-1}\right], f$ stands for the infiltration capacity of soil $\left[\mathrm{L} \mathrm{T}^{-1}\right], \alpha$ is the kinematic-wave resistance parameter, $m$ is an exponent, $Q_{\mathrm{f}}$ is the flow discharge $\left[\mathrm{L}^{3} \mathrm{~T}^{-1}\right]$, and $W$ is the width of overland flow [L]. Overland flow is treated as turbulent flow in this paper and thus $m=5 / 3$ and $\alpha=S^{0.5} / n$ are employed, where $n$ is Manning's roughness coefficient and $S$ is surface slope. For the convenience of numerical treatment and programming, Eq. (1a) can be expressed as:

$\frac{\partial h}{\partial t}+\frac{\partial(u h)}{\partial x}=\left(1-F_{\mathrm{Inf}}\right) \cdot I$

where $F_{\text {Inf }}=f / I$. The solution of the kinematic-wave equation requires only initial and upstream boundary conditions (van der Molen et al., 1995). The initial and boundary conditions imposed on Eq. (1c) are:

$$
\begin{array}{ll}
h(x, 0)=0, & 0 \leq x<L \\
h(0, t)=0, & 0 \leq t<\infty .
\end{array}
$$

The problem of overland flow reduces to the solution of Eq. (1c) subject to Eqs. (1b), (1d), and (1e).

\subsection{Overland soil erosion and sediment transport equation}

Equations used in the literature for rainfall-induced overland soil erosion and sediment transport vary significantly due to different understanding and treatments of the mechanisms responsible for soil erosion/deposition and sediment transport. Without detailed mechanisms-based derivations it is difficult to evaluate the soundness of the equations. It is therefore necessary to analyze the mechanisms involved in the soil erosion/deposition and sediment transport and to derive an equation for description of the rainfall-induced overland soil erosion and deposition processes and sediment transport. To that end a control volume for the overland flow and soil erosion/deposition and sediment transport is selected and shown in Fig. 1. The control volume is based on the following assumptions: (1) the flow and soil erosion/ deposition and sediment transport can be approximated as a onedimensional problem; (2) suspended sediments are fully mixed vertically at any location and thus the vertical sediment concentration gradient is negligible; (3) sediment concentration gradient caused by the dispersion term is negligible as compared to other terms (Boardman et al., 1990). Based on the above assumptions and the Reynolds transport theorem, one-dimensional mass conservation equation or continuity equation of suspended sediment in the overland flow on a unit width surface can be written as

$\frac{\partial}{\partial t} \int_{\mathrm{CV}} \rho_{\mathrm{S}} \mathrm{d} \forall+\int_{\mathrm{CS}} \rho_{\mathrm{S}} V \mathrm{~d} A=0$

where $\rho_{\mathrm{s}}=$ sediment density $\left[\mathrm{M} \mathrm{L}^{-3}\right]$ and $V$ =velocity vector of flow. The first integral in Eq. (2a) represents the accumulated mass of sediment in the control volume. The second integral stands for the net mass efflux of sediment through the entire control surface. The control volume has four control surfaces and a uniform concentration $c$. Then, Eq. (2a) can be rewritten as

$\frac{\partial(\operatorname{ch} \Delta x)}{\partial t}+\int_{\mathrm{CS} 1} \rho_{\mathrm{s}} V \mathrm{~d} A+\int_{\mathrm{CS} 2} \rho_{\mathrm{s}} V \mathrm{~d} A+\int_{\mathrm{CS} 3} \rho_{\mathrm{s}} V \mathrm{~d} A+\int_{\mathrm{CS} 4} \rho_{\mathrm{s}} V \mathrm{~d} A=0(2 \mathrm{~b})$ where $c=$ sediment concentration $\left[\mathrm{M} \mathrm{L}^{-3}\right]$. The equation states that the rate of accumulation of sediment mass in the control volume plus the

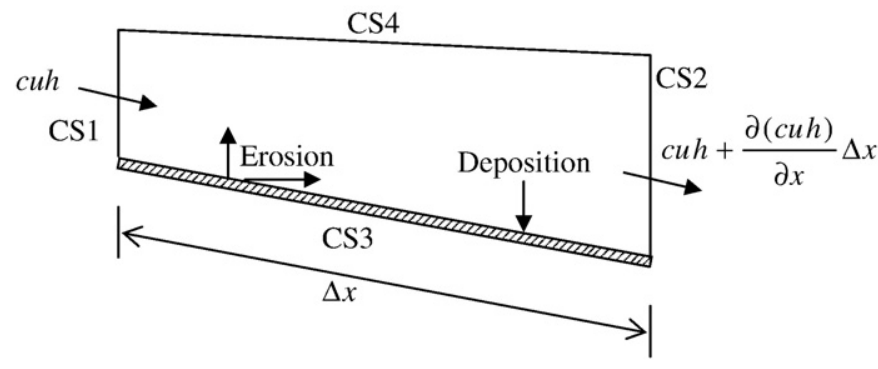

Fig. 1. Control volume for overland soil erosion and sediment transport. 
net mass efflux through all control surfaces (CS1-CS4) is zero. The net efflux is the mass flow rate of sediment out of the control volume minus the mass flow rate in. In other words, values of the integrals are negative if sediment entering the control volume and positive if leaving the control volume.

The sediment entering the control surface CS1 is

$\int_{\mathrm{CS} 1} \rho_{\mathrm{s}} V \mathrm{~d} A=-c u h$

The sediment leaving the control surface CS2 is

$\int_{\mathrm{CS} 2} \rho_{\mathrm{s}} V \mathrm{~d} A=c u h+\frac{\partial(\mathrm{cuh})}{\partial x} \Delta x$.

If the sediment concentration in rainfall is negligible, the net sediment flux through the control surface CS4 is zero, i.e.,

$\int_{\mathrm{CS} 4} \rho_{\mathrm{s}} V \mathrm{~d} A=0$

Sediment exchange at the control surface CS3 is complicated due to the entrainment and deposition of sediment. The exchange mainly involves two mechanisms or driving forces which include (i) the hydraulic erosion or deposition, $e_{\mathrm{h}}$, due to the interplay between the shearing force of water on the soil bed and the tendency of soil particles to settle under the force of gravity (Woolhiser et al., 1990), and (ii) the raindrop impact or rain splash on bare soil, $e_{\mathrm{r}}$, i.e.,

$\int_{\mathrm{CS} 3} \rho_{\mathrm{s}} V \mathrm{~d} A=-\left(e_{\mathrm{h}}+e_{\mathrm{r}}\right) \Delta x \cdot 1$.

Substituting Eqs. (2c)-(2f) into Eq. (2b) and dividing both sides of the resulting equation by $\Delta x$ yields

$\frac{\partial(\mathrm{ch})}{\partial t}+\frac{\partial(\mathrm{cuh})}{\partial x}=e_{\mathrm{h}}+e_{\mathrm{r}}$

where $e_{\mathrm{r}}=$ the rate of soil erosion caused by raindrop impact or rain splash $\left[\mathrm{M} \mathrm{L}^{-2} \mathrm{~T}^{-1}\right], e_{\mathrm{h}}=$ the net rate of hydraulic erosion (+) caused by flowing water or deposition (-) from the water $\left[\mathrm{M} \mathrm{L}^{-2} \mathrm{~T}^{-1}\right]$. Although there are no generally accepted expressions for hydraulic erosion of soil, it is widely recognized that the rate of soil erosion depends to a large extent on the sediment concentration defect $\left(c_{*}-c\right)$, where $c_{*}$, and $c$ are sediment concentration under equilibrium conditions and sediment concentration, respectively, representing the mass of sediment per unit volume of runoff $\left[\mathrm{M} \mathrm{L}^{-3}\right]$. The surface shear stress $\tau_{0}$ or shear velocity $u_{*}=\left(\tau_{0} / \rho\right)^{1 / 2}=(g h S)^{1 / 2}$ is also a dominant parameter affecting the erosion rate of cohesive sediment or consolidated soil (Prosser and Rustomji, 2000), where $\rho=$ water density $\left[\mathrm{M} \mathrm{L}^{-3}\right], g=$ the acceleration due to gravity $\left[\mathrm{L} \mathrm{T}^{-2}\right]$, and $S=$ surface slope along the flow direction. The hydraulic erosion occurs only when the shear velocity $u *$ is greater than the critical shear velocity $u_{*_{\mathrm{c}}}$ of the soil. The hydraulic erosion or the mass rate of entrainment of sediment into suspension can therefore be expressed as $e_{\mathrm{h}}=\xi\left(u_{*}-u_{*_{\mathrm{c}}}\right)$ $(c *-c)$, where $\xi=a$ dimensionless constant. The critical shear velocity can be estimated using the following equations (Chien and Wan, 1999):

$u_{*_{\mathrm{c}}}=\sqrt{\frac{1}{\rho}\left(0.068 D+\frac{3.73 \times 10^{-6}}{D}\right)}$

where $D=$ mean diameter of sediment [L]. It should be pointed out that Eq. (3b) was derived for steady flow and it is thus not applicable to the initial unsteady period of overland flow or the rising limb of hydrograph. Due to rain splash during the ponding period the top soil layer is usually detached from soil and sediments are suspended in the ponding water. Therefore, a zero critical shear velocity is used for the initial rising limb of overland flow and sediment transport. During the receding portion of hydrograph flow decreases and excess sediments $\left(c_{*}-c\right)$ deposit due to the settling velocity $w_{\mathrm{s}}$ of sediment particles. The mass rate of sediment deposition onto the bed can thus be expressed by $\zeta w_{s}\left(c_{*}-c\right)$, where $\zeta$ is a dimensionless constant. The settling velocity $\left(w_{s}\right)$ can be estimated using the following equation (Cheng, 1997):

$w_{\mathrm{s}}=\frac{v}{D}\left(\sqrt{25+1.2 d_{*}^{2}}-5\right)^{1.5}$

where, $v=$ kinematic viscosity $\left[\mathrm{L}^{2} \mathrm{~T}^{-1}\right]$ of water and $d_{*}=$ dimensionless particle parameter which is defined as

$d_{*}=\left(\frac{\Delta g}{v^{2}}\right)^{1 / 3} D$

where $\Delta=\left(\rho_{\mathrm{s}}-\rho\right) / \rho$. It is clear that the hydraulic deposition is driven by the joint effect of $w_{s}$ in the vertical direction and negative $\left(c_{*}-c\right)$ while the hydraulic erosion is caused by the combined action of the shear velocity $u_{*}$ in the flow direction and positive $\left(c_{*}-c\right)$. Consequently, it is inappropriate to use one single term like $\varphi w_{s}\left(c_{*}-c\right)(\varphi=$ constant $)$ to describe both the erosion and the deposition because their driving forces are not the same. It should be indicated that in terms of the net sediment exchange at the control surface CS3 the hydraulic erosion and the hydraulic deposition cannot occur simultaneously. Consequently, the rate of hydraulic erosion can be expressed as

$e_{\mathrm{h}}=\xi\left(u_{*}-u_{*}\right)\left(c_{*}-c\right) \quad$ if $c \leq c_{*}$

$e_{\mathrm{h}}=\zeta W_{\mathrm{s}}\left(c_{*}-c\right) \quad$ if $c>C_{*}$

where $\xi>0$ if $c_{*}>c$ and $u_{*}>u_{*}$; Otherwise, $\xi=0 . \zeta>0$ if $c_{*}<c$; Otherwise, $\zeta=0$.

Rainfall impact detaches soil particles and keeps them in suspension during rainfall. When the energy from rainfall ends or is reduced, the excess particles in suspension deposit. The erosion produced by raindrop impact or rain splash, $e_{\mathrm{r}}$, is dependent on the water depth (Woolhiser et al., 1990; Morgan et al., 1998). Increasing water depth causes the reduction in splash erosion. Based on the detachment equation for rainfall used in EUROSEM (Morgan et al. 1998) and the splash erosion equation adopted in KINEROS (Woolhiser et al., 1990) the rate $e_{\mathrm{r}}$ of the erosion produced by the raindrop impact or rain splash can be approximated as:

$e_{\mathrm{r}}=c_{0} \frac{I^{2}}{w_{\mathrm{s}}} \exp (-\eta h)$

where $c_{0}=$ the maximum sediment concentration produced by the raindrop impact in the overlying water at the end of the ponding time. The parameter $c_{0}$ depends on the rainfall intensity and soil and surface properties. $e_{\mathrm{r}}=0$ during the recession of the overland flow when rainfall stops $(I=0)$. The parameter $\eta$ represents the damping rate of the water depth and carries a dimension of $\left[\mathrm{L}^{-1}\right]$. Substituting Eqs. (3e), (3f), and (3g) into Eq. (3a) yields

$\frac{\partial(c h)}{\partial t}+\frac{\partial(c u h)}{\partial x}=\left[\xi\left(u_{*}-u_{*_{c}}\right)+\zeta w_{s}\right]\left(c_{*}-c\right)+c_{0} \frac{I^{2}}{w_{\mathrm{s}}} \exp (-\eta h)$.

For the convenience of mathematical manipulation, Eq. (4a) is recast as:

$c\left(\frac{\partial h}{\partial t}+\frac{\partial(u h)}{\partial x}\right)+h\left(\frac{\partial c}{\partial t}+u \frac{\partial c}{\partial x}\right)=u_{*}\left(c_{*}-c\right)+c_{0} \frac{I^{2}}{w_{\mathrm{s}}} \exp (-\eta h)$

where $u_{*_{w}}=\xi\left(u_{*}-u_{*_{c}}\right)+\zeta w_{s}$. Eq. (4b) can be rearranged as

$\frac{\partial c}{\partial t}+u \frac{\partial c}{\partial x}=\frac{u *_{\mathrm{w}}}{h}\left(c_{*}-c\right)+\frac{c_{0}}{h} \frac{I^{2}}{w_{\mathrm{s}}} \exp (-\eta h)-\frac{q}{h} c$.

In principle Eq. (5a) may be employed to predict distributions of sediment concentration $c$, that are usually characterized temporally 
by a steep rising limb followed by a receding limb, by assuming the initial concentration $c_{0}$ to be zero (Sander et al., 1996; Boardman and Favis-Mortlock, 1998; Heilig et al., 2001; Yu, 2003). However, for the overland sediment transport measured concentration curves often exhibit the first-flush phenomenon: a rapid falling limb followed by a prolonged receding limb. To simulate the overland sediment erosion and transport process with a non-zero initial sediment concentration, Eq. (5a) must be changed to a solvable form. To that end, replacing $c$ by $c Q_{\mathrm{f}} / Q_{\mathrm{f}}=C / Q_{\mathrm{f}}$ and $c_{*}$ by $c * Q_{\mathrm{f}} / Q_{\mathrm{f}}=C_{*} / Q_{\mathrm{f}}$, splitting each differential term of $C / Q_{\mathrm{f}}$ into two terms by taking their partial derivatives, respectively, and then multiplying both sides of the equation by $Q_{f}$, result in:

$$
\begin{aligned}
\frac{\partial C}{\partial t} & +u \frac{\partial C}{\partial x}+Q_{\mathrm{f}}\left(\frac{\partial\left(1 / Q_{\mathrm{f}}\right)}{\partial t}+u \frac{\partial\left(1 / Q_{\mathrm{f}}\right)}{\partial x}\right) C=\frac{u_{* \mathrm{w}}}{h}\left(C_{*}-C\right) \\
& +\frac{C_{0}}{h} \frac{I^{2}}{w_{\mathrm{s}}} \exp (-\eta h)-\frac{q}{h} C
\end{aligned}
$$

where $C=c Q_{\mathrm{f}}$ is the sediment transport rate or sediment discharge, $C_{*}=C * Q_{\mathrm{f}}$ denotes sediment transport capacity of surface runoff, $C_{0}=c_{0} Q_{\mathrm{f}}$ is the sediment discharge corresponding to $c_{0}$. It is assumed that $C_{0}=C_{*}$ due to the difficulty in the direct measurement of $c_{0}$. For simplicity the third term on the left hand side of Eq. (5b) without parameter $C$ is assumed as:

$\bar{Q}_{\mathrm{f}}=Q_{\mathrm{f}}\left(\frac{\partial\left(1 / Q_{\mathrm{f}}\right)}{\partial t}+u \frac{\partial\left(1 / Q_{\mathrm{f}}\right)}{\partial x}\right)=-\frac{1}{Q_{\mathrm{f}}}\left(\frac{\partial Q_{\mathrm{f}}}{\partial t}+u \frac{\partial Q_{\mathrm{f}}}{\partial x}\right)=-\frac{1}{Q_{\mathrm{f}}} \frac{\mathrm{d} Q_{\mathrm{f}}}{\mathrm{d} t}(5 \mathrm{c})$

where the total derivative of the flow discharge can be determined by using Eq. (1b) as

$$
\begin{aligned}
\frac{\mathrm{d} Q_{\mathrm{f}}}{\mathrm{d} t} & =\alpha W m h^{m-1} \frac{\mathrm{d} h}{\mathrm{~d} t}=\alpha W m h^{m-1}\left(\frac{\partial h}{\partial t}+u \frac{\partial h}{\partial x}\right) \\
& =\alpha W m h^{m-1}\left(\frac{\partial h}{\partial t}+\frac{\partial u h}{\partial x}-h \frac{\partial u}{\partial x}\right)=\alpha W m h^{m-1}\left(q-h \frac{\partial u}{\partial x}\right) \\
& =\frac{m Q_{\mathrm{f}}}{h}\left(q-h \alpha(m-1) h^{m-2} \frac{\partial h}{\partial x}\right)
\end{aligned}
$$

in which $q=I-f$ and Eqs. (1a) and (1b) are employed. In terms of the kinematic-wave approximation $\partial h / \partial x=S_{0}=$ soil surface slope along the flow direction (Martin and McCutcheon, 1999). Substituting $\partial h / \partial x=S_{0}$ into Eq. (5d) and combining Eqs. (5c) and (5d) gives

$\bar{Q}_{\mathrm{f}}=-\frac{1}{Q_{\mathrm{f}}} \frac{m Q_{\mathrm{f}}}{h}\left[q-(m-1) u S_{0}\right]=\frac{m}{h}\left[(m-1) u S_{0}-q\right]$

where the term $(m-1) u S_{0}$ is much greater than $q$ in general. Therefore, the right-hand side of Eq. (5e) is always positive on steep slopes where the kinematic-wave model is applicable. Turbulent flow is commonly assumed and thus $m=5 / 3$ is widely adopted for overland flow (Woolhiser et al., 1990; Morgan et al., 1998). Substituting $m=5 / 3$ into Eq. (5e) and neglecting $q$ yields $\bar{Q}_{\mathrm{f}}=10 u S_{0} / 9 h=1.11 \alpha h^{-1 / 3} S_{0}$.

Substituting Eq. (5e) into Eq. (5b) and rearranging the terms yields

$\frac{\partial C}{\partial t}+u \frac{\partial C}{\partial x}=E C_{*}+G C_{0} \exp (-\eta h)-(Y+E) C$

in which $E=u_{* \mathrm{w}} / h, G=I^{2} /\left(h w_{\mathrm{s}}\right)$, and $Y=\bar{Q}_{\mathrm{f}}+q / h$ are introduced. Eq. (6a) describes the change of sediment transport rate or sediment discharge $C$ in overland flow due to the rainfall erosion and thus is termed as sediment transport rate-based equation. It is apparent that for a continuous, steady flow $\bar{Q}_{\mathrm{f}}=0$ in Eq. (5c) and then Eq. (6a) reduces back to Eq. (5a). It implies that Eq. (5a) and the commonly used advection equation of sediment transport are a special form of Eq. (6a). Consequently, Eq. (6a) is a generalized sediment transport equation. Eq. (6a) is also subject to the initial and boundary conditions:

$$
\begin{array}{ll}
C(x, 0)=0, & 0 \leq x<L \\
C(0, t)=0, & 0 \leq t<\infty .
\end{array}
$$

The sediment transport capacity $C_{*}$ can be estimated using the following equations presented by Beasley et al. (1980):

$$
\begin{aligned}
& \frac{60 C_{*}}{W}=146 S\left(\frac{60 Q_{\mathrm{f}}}{W}\right)^{1 / 2} \\
& \text { or } \quad C_{*}=146 S\left(\frac{W Q_{\mathrm{f}}}{60}\right)^{1 / 2}\left(\text { for } Q_{\mathrm{f}} / W \leq 0.046 \mathrm{~m}^{2} \mathrm{~min}^{-1}\right) \\
& \frac{60 C_{*}}{W}=14600 S\left(\frac{60 Q_{\mathrm{f}}}{W}\right)^{2} \\
& \text { or } \quad C_{*}=14600 S Q_{\mathrm{f}}^{2}\left(\frac{60}{W}\right)\left(\text { for } Q_{\mathrm{f}} / W>0.046 \mathrm{~m}^{2} \mathrm{~min}^{-1}\right) .
\end{aligned}
$$

Eqs. (7a) and (7b) are found to be ineffective in describing sediment deposition process during the receding period of overland flow. The following equation proposed by Prosser and Rustomji (2000) is employed to determine the sediment transport capacity of receding overland flow:

$q_{\mathrm{s}}=k q_{\mathrm{w}}^{\eta} S^{\gamma}$

where, $q_{\mathrm{s}}=$ sediment transport capacity per unit width $\left[\mathrm{L}^{3} \mathrm{~T} \mathrm{~L}^{-1}\right], q_{\mathrm{w}}=$ discharge per unit width $\left[\mathrm{L}^{2} \mathrm{~T}^{-1}\right], k, \eta$, and $\gamma$ are empirical or theoretically derived constants. It should be noted that the time $t=0$ corresponds to the beginning of overland flow instead of rainfall. Soil surface is impacted by raindrops and sediment particles are suspended and mixed in overlying water in the ponding time but there is no sediment transport in the soil surface until the overland flow begins. Therefore, it is reasonable for overland flow to have a zero initial sediment transport rate but a non-zero initial concentration value of $c(x, 0)$, since $C=c Q_{\mathrm{f}}$ and $Q_{\mathrm{f}}=0$ at $t=0$. As $c=C / Q_{\mathrm{f}}$ and both $C$ and $Q_{\mathrm{f}}$ are zero at $t=0$, the value $(0 / 0)$ of $c(x, 0)$ is thus uncertain but calculable. One way to determine the initial value of $c\left(x, t_{\text {initial }}\right)$ is to take $t_{\text {initial }}=5 \mathrm{~s}$ or even a shorter time, for instance, $2 \mathrm{~s}$, then $c\left(x, t_{\text {initial }}\right)$ can be found as $C\left(x, t_{\text {initial }}\right) /$ $Q_{f}\left(x, t_{\text {initial }}\right)$. If the sediment transport rate of the flow during the initial period is assumed to be equal to its sediment transport capacity, the concentration can be calculated as $c=C_{*}\left(x, t_{\text {initial }}\right) / Q_{\mathrm{f}}\left(x, t_{\text {initial }}\right)=[146 S$ $\left.\left(W Q_{\mathrm{f}} / 60\right)^{1 / 2}\right] / Q_{\mathrm{f}}=146 S\left[W /\left(60 Q_{\mathrm{f}}\right)\right]^{1 / 2}$. It is obvious that if flow discharge $Q_{\mathrm{f}}$ approaches to 0 , sediment concentration $c$ tends to be infinite large instead of zero conventionally assumed. In general, the value of $c(x$, $t_{\text {initial }}$ ) is not necessarily the maximum. It is possible to obtain a peak concentration from $c=C / Q_{\mathrm{f}}$, although the initial concentration is not zero. Consequently, the transport rate-based model provides an effective and flexible tool for simulating the complicated rainfall-induced soil erosion and subsequent sediment transport. Eqs. (1a)-(1e) and (6a)-(6c) can be employed as fundamental equations for simulating overland flow and soil erosion and sediment transport.

\section{Numerical solutions for proposed model}

The objective of numerical method is to solve Eq. (6a) for sediment transport rate $C(x, t)$ and then concentration $c(x, t)$ at the outlet. To that end, the flow depth $h$ should be calculated first at each spatial grid from the overland flow Eq. (1a).

\subsection{Numerical scheme for kinematic-wave equation}

Several numerical techniques are available for the solution of the kinematic-wave equation. One of the most widely used second-order finite-difference schemes is the Lax-Wendroff (LW) scheme. The essence of the LW scheme is in the Taylor series expansion of the dependent variable $h$ by neglecting the terms whose order is higher than two, i.e.,

$h(x, t+\Delta t)=h(x, t)+\Delta t \frac{\partial h}{\partial t}+\frac{(\Delta t)^{2}}{2 !} \frac{\partial^{2} h}{\partial t^{2}}$ 
where $\partial h / \partial t$ is obtained from Eq. (1a) as

$\frac{\partial h}{\partial t}=q-m \alpha h^{m-1} \frac{\partial h}{\partial x}$

where $q=I-f$ is the lateral inflow per unit width. $\partial^{2} \mathrm{~h} / \partial \mathrm{t}^{2}$ can be found by differentiating Eq. (8b) as:

$\frac{\partial^{2} h}{\partial t^{2}}=\frac{\partial q}{\partial t}-\alpha \frac{\partial}{\partial x}\left[m h^{m-1}\left(q-m \alpha h^{m-1} \frac{\partial h}{\partial x}\right)\right]$.

Substituting Eqs. (8b) and (8c) into Eq. (8a) and applying the FTCS (forward time and centered space) differencing scheme yields the following finite-difference solution of the kinematic-wave equation (Woolhiser, 1975; Singh, 1996):

$$
\begin{aligned}
h_{j}^{i+1}= & h_{j}^{i}+\Delta t\left(q_{j}^{i}-m \alpha \frac{h_{j+1}^{i^{m-1}}+h_{j-1}^{i^{m-1}}}{2} \frac{h_{j+1}^{i}-h_{j-1}^{i}}{2 \Delta x}\right)+\frac{(\Delta t)^{2}}{2} \frac{q_{j}^{i+1}-q_{j}^{i}}{\Delta t} \\
& -m \alpha \frac{(\Delta t)^{2}}{2 \Delta x}\left[\frac{h_{j+1}^{i^{m-1}}+h_{j}^{m^{m-1}}}{2}\left(\frac{q_{j+1}^{i}+q_{j}^{i}}{2}-m \alpha \frac{h_{j+1}^{i^{m-1}}+h_{j}^{i^{m-1}}}{2} \frac{h_{j+1}^{i}-h_{j}^{i}}{\Delta x}\right)\right. \\
& \left.-\frac{h_{j}^{i^{m-1}}+h_{j-1}^{i^{m-1}}}{2}\left(\frac{q_{j}^{i}+q_{j-1}^{i}}{2}-m \alpha \frac{h_{j}^{i^{m-1}}+h_{j-1}^{i^{m-1}}}{2} \frac{h_{j}^{i}-h_{j-1}^{i}}{\Delta x}\right)\right]
\end{aligned}
$$

where superscript $i$ denotes the time step and subscript $j$ stands for the distance step; $\Delta x$ and $\Delta t$ represent the distance and time step lengths, respectively. For the downstream boundary, Eq. (9) is no longer valid and the following first-order scheme is employed:

$h_{j}^{i+1}=h_{j}^{i}+\Delta t\left(q_{j}^{i}-m \alpha \frac{h_{j}^{i^{m-1}}+h_{j-1}^{i m-1}}{2} \frac{h_{j}^{i}-h_{j-1}^{i}}{\Delta x}\right)$.

To ensure the numerical stability of the LW scheme, the Courant condition must be satisfied, i.e.,

$\frac{\Delta t}{\Delta x} \leq \frac{1}{\alpha m h^{m-1}}$.

Once the flow depth is calculated, then flow velocity can be determined using Eq. (1b) and the solute transport equation can be subsequently solved.

\subsection{Numerical scheme for soil erosion and sediment transport equation}

Due to the lack of dispersion term, Eqs. (6a)-(6c) is an advectiondominated transport equation. It has been demonstrated that the semi-Lagrangian (SL) scheme, based on the method of characteristics and interpolation between grid points, is particularly suitable for numerical simulation of advection-dominated transport processes and is capable of providing high accuracy with minimal computational effort (Holly and Preissmann, 1977; Holly and Usseglio-Polatera, 1984; Karpik and Crockett, 1997). In order to utilize the semi-Lagrangian approach, Eq. (6a) can be recast as

$\frac{\mathrm{d} C}{\mathrm{~d} t}=E C_{*}+G C_{0} \exp (-\eta h)-(Y+E) C$.

Eq. (12) is the total derivative of the transport rate $C$ along the solute particle trajectory or the characteristic line defined by

$\frac{\mathrm{d} x}{\mathrm{~d} t}=u$
Integrating Eq. (12) from $\left(x_{d}, t_{i}\right)$ to $\left(x_{a}, t_{i+1}\right)$ along the characteristic line Eq. (13) and using the explicit second-order Runge-Kutta (midpoint) method (Press et al., 1988) lead to

$C_{a}^{i+1}=C_{d}^{i}+\int_{t_{i}}^{t_{i+1}}\left[E C_{*}+G C_{0} \exp (-\eta h)-(Y+E) C\right] \mathrm{d} t$

$x_{d}=x_{a}+\int_{t+\Delta t}^{t} u(x, t) \mathrm{d} t=x_{a}-\int_{t}^{t+\Delta t} u(x, t) \mathrm{d} t=x_{a}-\Delta t u\left(\frac{x_{d}+x_{a}}{2}, t_{n+1 / 2}\right)$

where subscripts $a$ and $d$ represent the arrival (at time $t+\Delta t$ ) and departure (at time $t$ ) points of the considered solute particle. Applying a trapezoidal integration rule to Eq. (14a) results in

$$
\begin{aligned}
C_{a}^{i+1}= & C_{d}^{i}+\frac{\Delta t}{2}\left\{\left[E C_{*}+G C_{0} \exp (-\eta h)-(Y+E) C\right]_{d}^{i}\right. \\
& \left.+\left[E C_{*}+G C_{0} \exp (-\eta h)-(Y+E) C\right]_{a}^{i+1}\right\} .
\end{aligned}
$$

Rearranging terms in Eq. (15) gives

$C_{a}^{i+1}=\frac{\lambda C_{d}^{i}+\beta}{1+\varepsilon\left(Y^{i+1}+E^{i+1}\right)}$

in which

$\varepsilon=\Delta t / 2$

$\lambda=1-\varepsilon\left(Y^{i}+E^{i}\right)$

$\beta=\varepsilon\left\{\left.\left[E C_{*}+G C_{0} \exp (-\eta h)\right]\right|_{d} ^{i}+\left.\left[E C_{*}+G C_{0} \exp (-\eta h)\right]\right|_{a} ^{i+1}\right\}$.

Eq. (16a) shows that the transport rate $C$ at each grid point $x_{a}$ (the "arrival" point) at the new time $t+\Delta t$ can be determined using the transport rate of the departure point $x_{d}$ at the previous time $t$. In principle, the transport rate at all grid points at time $t$ should be

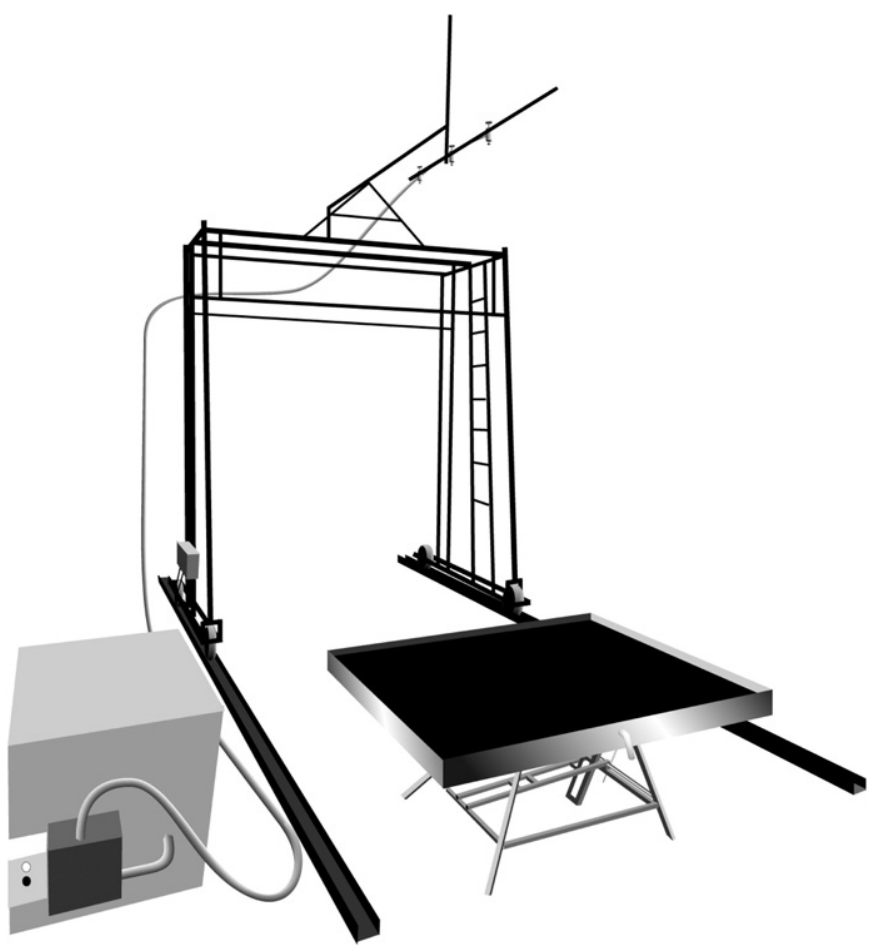

Fig. 2. Sketch of laboratory set-up with square soil flume, support structure for the rainfall simulator and hydraulic circuit (constant head reservoir, pump, hose and nozzles). 
known. However, the departure point $x_{d}$ typically will not fall on a grid point and thus the location of the departure point $x_{d}$ must be estimated first. Then, the transport rate $C$ at the departure point $x_{d}$ can be interpolated using the known values of two neighbouring grid points and finally replacing that value at $x_{a}$ according to Eq. (16a).

Numerous interpolation methods exist (Press et al., 1988). Cubic splines are the most popular interpolating functions. These smooth functions do not have the significant oscillatory behavior that is characteristic of high-degree polynomial interpolators, e.g., the Lagrangian interpolator, Hermite interpolator, and similar schemes. Moreover, cubic splines have the lowest interpolation error of all fourth-order interpolating polynomials. Therefore, the commonly used natural cubic splines were adopted to perform the required interpolation. The "natural" implies that the second derivative of the spline function is set to zero at the endpoints because this provides a boundary condition that completes the system of $n-2$ equations, leading to a simple tridiagonal system which can be solved easily. Once the solute transport rate $C$ is available, the solute concentration $c$ can be easily obtained. Since the splashed sediments are suspended in water and accumulated on the soil surface in the ponding time, the availability of sediments for erosion is high in the initial runoff period and becomes lower latter due to the increase in water depth. Although the runoff rate may be greater in the remainder of the storm duration, the storage of detached sediments available for washoff is almost depleted or limited, causing a significant decline in sediment concentration. Sediment erosion and transport tends to be steady when rainfall and flow are steady, producing a constant sediment concentration. Such a sediment concentration variation is difficult to simulate directly using the concentration-based advection-diffusion equation unless the solution conditions are properly defined.

\section{Test of proposed model and discussion of results}

To test the efficacy of the transport rate-based model, a series of laboratory experiments were conducted using a soil flume and a rainfall simulator.

\subsection{Experimental set-up}

A sketch of the laboratory set-up of experimental flume is presented in Fig. 2. Laboratory experiments were conducted using a soil flume with a sprinkling-type rainfall simulator and an adjustable slope.

Dimensions of the soil flume were $2 \mathrm{~m}$ long, $2 \mathrm{~m}$ wide, and $0.12 \mathrm{~m}$ high. Surface runoff and free percolation water were collected at the end of the flume. The soil material used in the experiments consisted of $11.5 \%$ clay, $9.8 \%$ silt, and $78.7 \%$ sand and mean diameter of sediment is about $0.4 \mathrm{~mm}$, as shown in Fig. 3. The original soil was sieved to remove coarse rock and organic debris, prior to being uniformly spread in the flume. To obtain a flat surface, a sharp edged straight blade that could ride on the top edge of the sidewalls of the flume was used to remove excess soil. The blade was adjusted such that the soil level in the flume equalled the retaining plate at the downstream end of the flume. Afterwards, the soil was gently tapped with a wooden block to attain a uniform dry bulk density of approximately $1565 \mathrm{~kg} / \mathrm{m}^{3}$. The resulting soil surface was smooth, without roughness elements. The soil placed
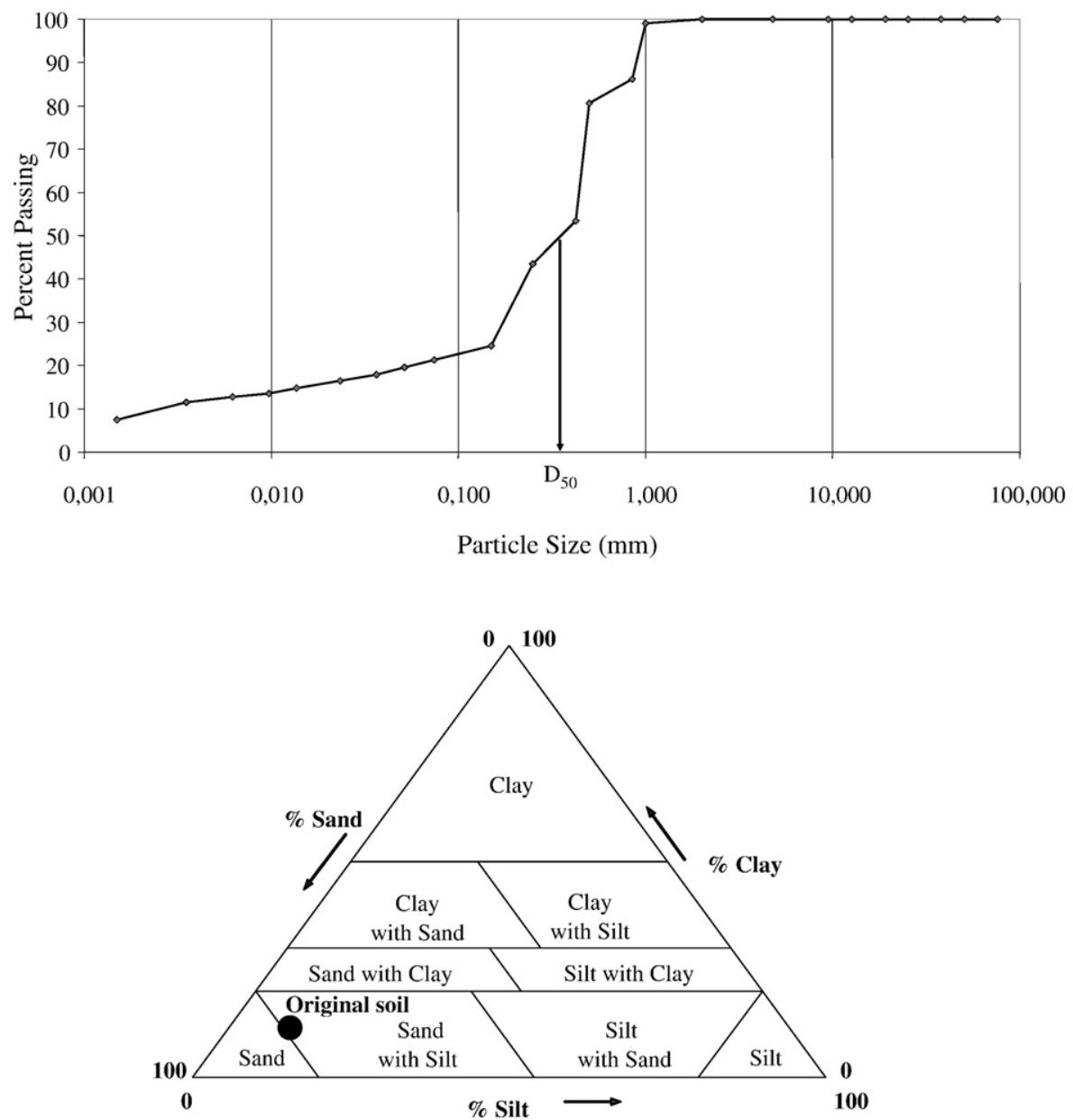

Fig. 3. Grain-size characteristics of the soil material placed in the soil flume. Top: Granulometric curve; and Bottom: Position in the Feret triangle. 
in the flume had a uniform thickness of $0.10 \mathrm{~m}$. The flume slope was $10 \%$.

The basic components of the rainfall simulator were three equally spaced downward-oriented full-cone nozzles, a support structure in which the nozzles were installed, and the connections with the water supply and the pump, as shown in Fig. 2. The spacing between the nozzles was $0.5 \mathrm{~m}$. The nozzles had a height of $2.49 \mathrm{~m}$ above the geometric centre of the soil flume. A simulated rainfall pattern with an average intensity of $3.53 \mathrm{~mm} / \mathrm{min}$ was applied to the soil flume surface. Samples of overland flow and accompanying sediment transport were collected at the downstream end of the soil flume using metal containers. The amount of sediment transported by overland flow was estimated by drying of runoff samples in a low temperature oven. After drying the runoff samples the transported sediments underwent granulometric characterization in order to evaluate how their granulometry evolved over time. There were two distinct phases in this step: one using optical spectrophotometry (laser diffraction particle size analyzer - LS 230 Beckman Coulter, Inc.), and the other using conventional sieving. The collected data from three experiments are shown in Table 1.

\subsection{Model applications}

The transport rate-based model was applied to simulate rainfall simulator-induced overland flow and sediment transport over a soil flume. Parameters involved in the model were estimated using the data collected from the laboratory experiments. Estimated values of parameters involved in the model are listed in Table 2. Fig. 4 shows a comparison between numerically simulated and experimentally measured flow discharge, sediment transport rate, and sediment concentration for the first run. Fig. 4(a) shows that the simulated hydrograph is in very good agreement with the measured hydrograph. Fig. 4(b) indicates that the computed sediment transport rate fits the measured one well in general although two measured data points deviate from the computed transport rate curve. Fig. 4(c) illustrates that the computed sediment concentration matches the measured data well except one data point. In the second run we noticed some lateral flow and sediment transport due to the formation of a lateral rill, causing some deviations of measured data from the simulated sediment transport rate and concentration distributions in Fig. 5(b) and (c). Figs. 6(a), (b), and (c) demonstrate good agreements between the computed and measured flow discharge, sediment transport rate, and sediment concentration for the third run. Overall, the transport

Table 1

Experimental results of flow discharge $(Q)$, sediment transport rate $(C)$ and calculated concentration $(c)$ for the 3 experiments

\begin{tabular}{lrllr}
\hline No. of experiment & Time $(\mathrm{s})$ & $Q(\mathrm{l} / \mathrm{s})$ & $C(\mathrm{~g} / \mathrm{s})$ & $c\left(\mathrm{~kg} / \mathrm{m}^{3}\right)$ \\
\hline Run-1 & 0.00 & 0.000 & 0.000 & 0.00 \\
& 8.00 & 0.108 & 1.669 & 15.50 \\
& 87.70 & 0.232 & 2.190 & 9.45 \\
& 164.50 & 0.216 & 1.651 & 7.64 \\
& 240.45 & 0.217 & 1.603 & 7.38 \\
Run-2 & 306.65 & 0.012 & 0.033 & 2.70 \\
& 0.00 & 0.000 & 0.000 & 0.00 \\
& 7.60 & 0.114 & 0.647 & 5.69 \\
& 56.15 & 0.236 & 2.035 & 8.62 \\
& 133.05 & 0.224 & 1.908 & 8.53 \\
& 239.15 & 0.221 & 1.554 & 7.04 \\
& 345.60 & 0.228 & 1.417 & 6.20 \\
Run-3 & 400.95 & 0.122 & 0.383 & 3.15 \\
& 0.00 & 0.000 & 0.000 & 0.00 \\
& 7.55 & 0.149 & 0.703 & 4.71 \\
& 53.85 & 0.212 & 0.837 & 3.94 \\
& 130.25 & 0.224 & 0.875 & 3.91 \\
& 295.80 & 0.236 & 0.936 & 3.97 \\
& 462.15 & 0.221 & 0.868 & 3.92 \\
& 508.45 & 0.025 & 0.019 & 0.76 \\
\hline
\end{tabular}

Table 2

Calibration parameter and values used in the simulation of runoff and sediment transport

\begin{tabular}{lccc}
\hline Calibration parameter & Run-1 & Run-2 & Run-3 \\
\hline Infiltration $\left(F_{\text {Inf }} \%\right)$ & 15 & 15 & 15 \\
Manning's roughness $(n)$ & 0.0265 & 0.0265 & 0.0265 \\
Erosion rate $(\xi)$ & 0.021 & 0.021 & 0.011 \\
$\kappa$ & 20.0 & 20.0 & 22.0 \\
$\eta$ & 1.38 & 1.38 & 1.38 \\
$\gamma$ & 1.0 & 1.0 & 1.0 \\
$a$ & 0.1 & 0.1 & 0.1 \\
\hline
\end{tabular}

rate-based model developed in this paper is capable of reproducing main characteristics and processes of overland flow and sediment transport.

Flow discharges in the three runs were almost the same during the steady state due to the constant rainfall intensity $(3.53 \mathrm{~mm} / \mathrm{min})$, as shown in Table 1. Therefore, there were no significant changes in flow depth in the three runs. Flow depth in the soil flume varied both spatially and temporally due to non-uniform soil erosion caused by scattered shields and rills. There were some isolated soils exposed above flow surface and experienced stronger rain splash than the areas with relative deep flow depth (few millimeters). Fig. 4c displays a firstflush phenomenon observed in the first run. Since more and more fine sediment particles (primarily small clays and silts) on surface were eroded, shields composed of large particles started developing at the end of the first run, leading to a lower sediment concentration at the beginning of the second run, as indicated in Table 1 and Fig. 5c. The
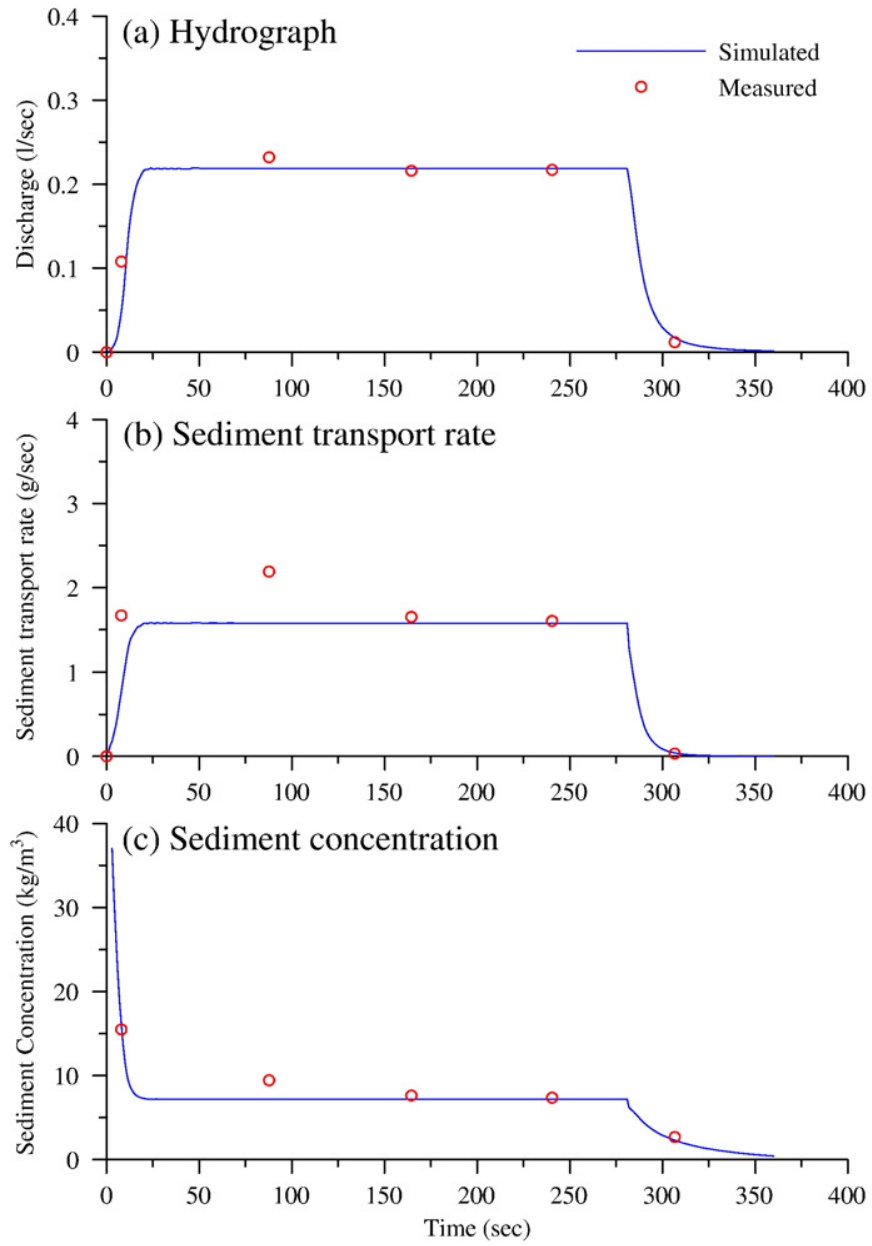

Fig. 4. Comparison between observed and simulated results for Run-1. 
time interval between the first and the second run was $48 \mathrm{~h}$ and $30 \mathrm{~min}$ and the interval between the second and the third run was $43 \mathrm{~h}$. Before the start of a new run, soil surface was levelled using the blade mentioned in the previous section so that rills formed during previous run were filled and the resulting soil surface was smooth. Significant shielding phenomenon was observed in the third run, reducing both sediment transport rate and concentration dramatically, as demonstrated in Fig. 6. Comparisons among the corresponding parameter values listed in Table 2 also illustrate that the value of parameter $\xi$ (erosion rate) drops from 0.021 in runs- 1 and 2 to 0.011 in run-3, clearly indicating that the shielding effect is cumulative and it diminishes erosion over time.

It should be noted that the initial high sediment concentrations shown in Figs. 4-6 are not artifacts of a small initial discharge because the sediment concentrations are calculated based on the dry weights of sediments, as mentioned in the previous section. More sediments were indeed collected during the initial sampling of each run. In addition, the initial discharges $(0.108 \mathrm{l} / \mathrm{s}, 0.114 \mathrm{l} / \mathrm{s}$, and $0.149 \mathrm{l} / \mathrm{s})$ used in the computations of initial sediment concentrations are at the same order of magnitude as the steady state discharges and thus are not small, as shown in Table 1. Main differences between this model and other calibrated, process-based erosion models include (1) this model is able to simulate overland soil erosion and sediment transport processes with any type of initial sediment concentrations such as an initial sediment concentration of zero and any non-zero initial sediment concentration including the first-flush type of sediment concentrations, and (2) this model treats erosion and deposition as two different processes. An implicit assumption involved in existing erosion models
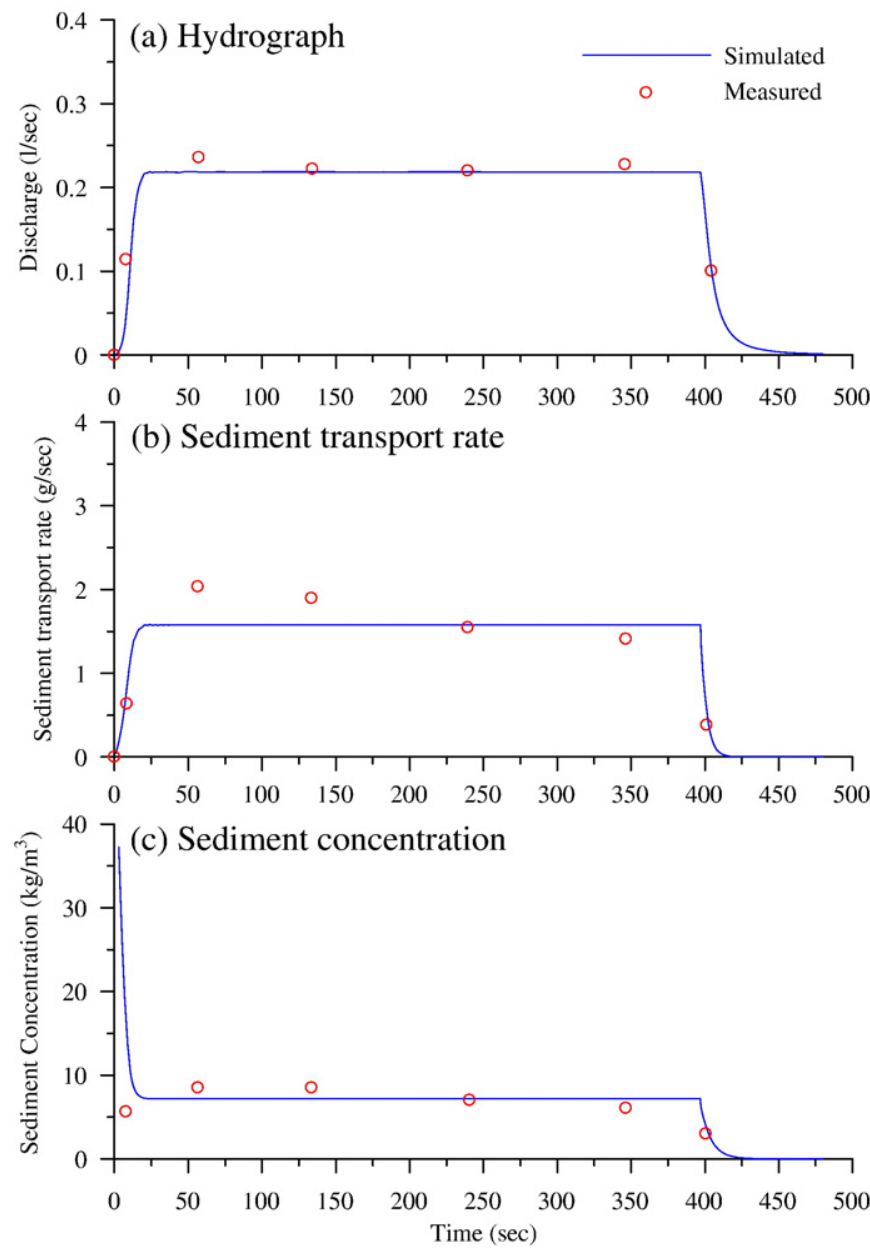

Fig. 5. Comparison between observed and simulated results for Run-2.

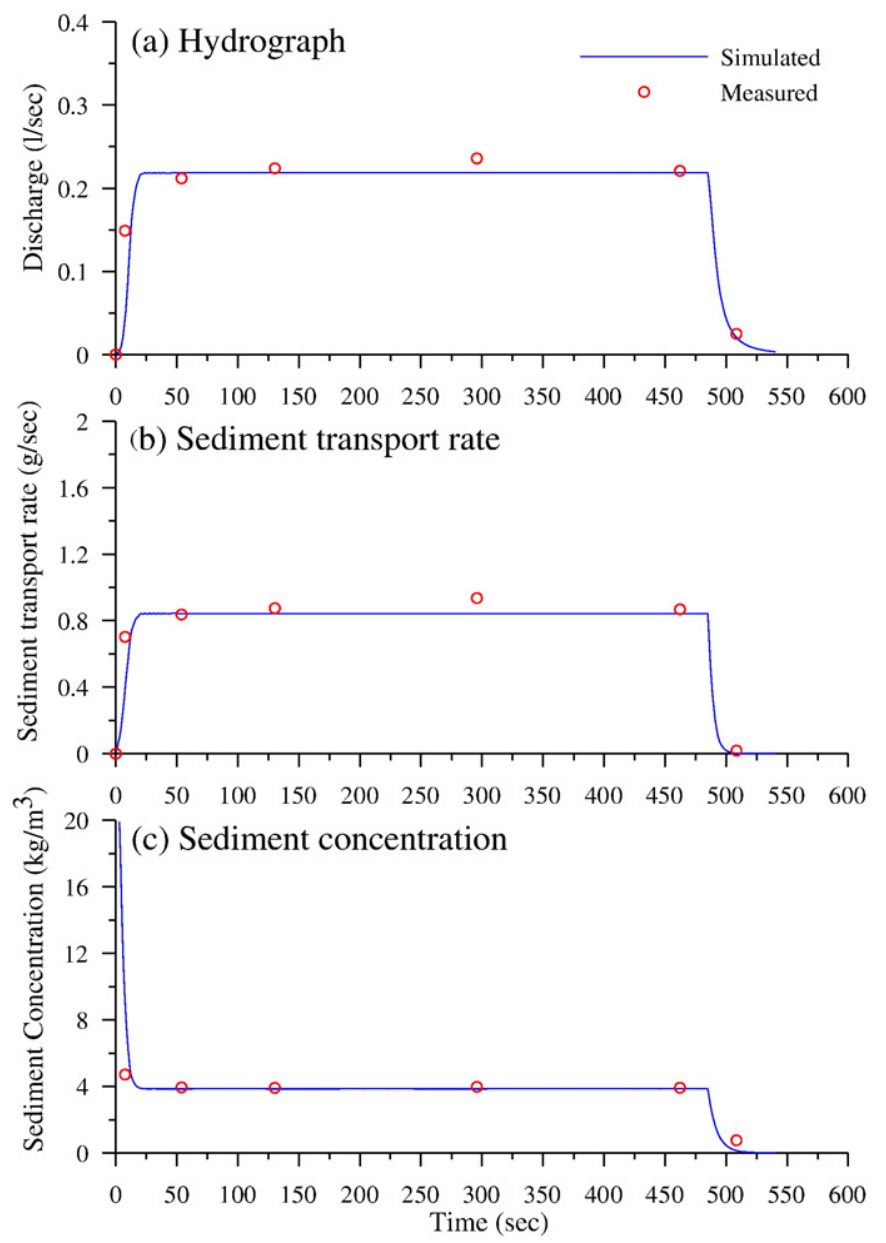

Fig. 6. Comparison between observed and simulated results for Run-3.

is that sediment transport capacity is independent of sediment transport regime (erosion/deposition) and has a unique vale for given soil type, flow rate, and slope. However, Polyakov and Nearing (2003) found that sediment transport capacity exhibits a hysteresis phenomenon that depends on the sediment regime. The differences and evidence mentioned above clearly indicate the major advantages of the new model developed in this paper over the existing erosion models.

It should be pointed out that it is possible that sediment concentration first rises from a non-zero value and reaches a peak in a very short time, as shown in Figs. 3 and 4 of Heilig et al. (2001), and then declines. In theory, the model developed in this paper is also able to simulate such a process. Due to sampling limitations we were unable to observe the sediment concentration variation in the very first few seconds. However, in laboratory experiments we did notice that it is the very turbid water (with high sediment concentration) rather than the clear water (with zero sediment concentration) first entered the sediment sampling container. Anyway, in this paper we ignore the possibility that concentration first rises because it is physically unimportant. A sensor-based technology may be employed to conduct real-time sediment concentration sampling so that the sediment concentration variation during the ponding period and thus in the very first few seconds of overland flow can be determined.

\section{Conclusions}

A physically-based one-dimensional mathematical model is developed for simulating overland flow and sediment transport under constant rainfall. The model is comprised of (i) the kinematic- 
wave overland flow equation, (ii) a generalized and transport ratebased advective equation for overland sediment transport, and (iii) a semi-Lagrangian algorithm for numerical solution of the sediment transport equation. A series of soil flume experiments under constant rainfalls are also conducted to simulate the overland flow and sediment transport and to test the sediment transport rate-based model. Both numerical solutions of the sediment transport rate-based model and experimental results show that (i) hydrographs display an initial rising limb, followed by a constant discharge and then a recession limb; (ii) sediment transport rate graphs exhibit the distributions similar to the hydrographs; and (iii) sediment concentration graphs show an initial steep-receding limb, followed by a constant distribution, and ended with a receding tail. The numerically simulated hydrographs, sediment transport rate, and sediment concentration are in good agreement with corresponding experimental measurements, demonstrating the laboratory proof-of-concept of the transport rate-based model.

\section{Acknowledgments}

The research reported in this paper was supported by USGS and Louisiana Water Resources Research Institute. The laboratory experiments were also funded by the Foundation for Science and Technology of the Portuguese Ministry of Science and Technology, Lisbon, Portugal.

\section{References}

Aksoy, H., Kavvas, M.L., 2005. A review of hillslope and watershed scale erosion and sediment transport models. Catena 64 (2-3), 247-271.

Beasley, D.B., Huggins, L.F., Monke, E.J., 1980. ANSWERS: a model for watershed planning. Trans. ASAE 23 (4), 938-944.

Boardman, J., Favis-Mortlock, D., 1998. Modelling Soil Erosion by Water. Springer-Verlag, Berlin.

Boardman, J., Foster, I.D.L., Dearing, J.A., 1990. Soil Erosion on Agricultural Land. John Wiley and Sons, New York, USA.

Cheng, N.-S., 1997. Simplified settling velocity formula for sediment particle. J. Hydraul. Eng. 123 (2), 149-152.

Chien, N., Wan, Z., 1999. Mechanics of Sediment Transport. ASCE Press, Reston.

Folly, A., Quinton, J., Smith, R., 1999. Evaluation of the EUROSEM model using data from the Catsop watershed, The Netherlands. Catena 37 (3-4), 507-519.

Hairsine, P.B., Beuselinck, L., Sander, G.C., 2002. Sediment transport through an area of net deposition. Water Resour. Res. 38 (6), 1086. doi:10.1029/2001WR000265.

Heilig, A., DeBruyn, D., Walter, M.T., Rose, C.W., Parlange, J.-Y., Steenhuis, T.S., Sander, C., Hairsine, P.B., Hogarth, W.L., Walker, L.P., 2001. Testing a mechanistic soil erosion model with a simple experiment. J. Hydrol. 244 (1-2), 9-16.
Holly, F.M., Preissmann, A., 1977. Accurate calculation of transport in two-dimensions. J. Hydraul. Div. 103 (11), 1259-1277.

Holly, F.M., Usseglio-Polatera, J.-D., 1984. Accurate two-dimensional simulation of advective-diffusive-reactive transport, J. Hydraul. Eng. 127 (9), 728-737.

Karpik, S.R., Crockett, S.R., 1997. Semi-Lagrangian algorithm for two-dimensional advection-diffusion equation on curvilinear coordinate meshes. J. Hydraul. Eng. 123 (5), 389-401.

Martin, J.L., McCutcheon, S.C., 1999. Hydrodynamics and Transport for Water Quality Modeling, 7. CRC Press, Inc., Boca Raton, FL, USA, pp. 7-220.

Morgan, R.P.C., Quinton, J.N., Smith, R.E., Govers, G., Poesen, J.W.A., Auerswald, K., Chisci, G., Torri, D., Styczen, M.E., 1998. The European Soil Erosion Model (EUROSEM): a dynamic approach for predicting sediment transport from fields and small catchments. Earth Surf. Processes Landf. 23 (6), 527-544.

Parlange, J.-Y., Hogarth, W.L., Rose, C.W., Sander, G.C., Hairsine, P., Lisle, I., 1999 Addendum to unsteady soil erosion model. J. Hydrol. 217 (1-2), 149-156.

Polyakov, V.O., Nearing, M.A., 2003. Sediment transport in rill flow under deposition and detachment conditions. Catena 51 (1), 33-43.

Press, W.H., Flannery, B.P., Teukolsky, S.A., Vetterling, W.T., 1988. Numerical Recipes. Cambridge University Press, New York, USA.

Prosser, I.P., Rustomji, P., 2000. Sediment transport capacity relations for overland flow. Prog. Phys. Geogr. 24 (2), 179-193.

Rose, C.W., 2001. Soil erosion models and implications for conservation of sloping tropical lands. In: Stott, D.E., Mohtar, R.H., Steinhardt, G.C. (Eds.), Sustaining the Global Farm, International Soil Conservation Organization (ISCO), Netherlands, pp. 852-859.

Rose, C.W., Hogarth, W.L., 1998. Process-based approaches to modeling soil erosion. In: Boardman, J., Favis-Mortlock, D. (Eds.), Modeling Soil Erosion by Water. . NATO-ASI Global Change Series. Springer-Verlag, Heidelberg, pp. 259-270.

Sander, G.C., Hairsine, P.B., Rose, C.W., Cassidy, D., Parlange, J.-Y., Hogarth, W.L., Lisle, I.G. 1996. Unsteady soil erosion model, analytical solutions and comparison with experimental results. J. Hydrol. 178 (1-4), 351-367.

Sander, G.C., Hairsine, P.B., Beuselinck, L., Govers, G., 2002. Steady state sediment transport through an area of net deposition: multisize class solutions. Water Resour. Res. 38 (6), 1087. doi:10.1029/2001WR000323.

Singh, V.P., 1996. Kinematic Wave Modeling in Water Resources: Surface-Water Hydrology. John Wiley \& Sons, New York, USA.

Singh, V.P., Woolhiser, D.A., 2002. Mathematical modeling of watershed hydrology. J. Hydrol. Eng. 7 (4), 270-292.

Smith, R.E., Goodrich, D.C., Quinton, J.N., 1995. Dynamic, distributed simulation of watershed erosion: The KINEROS2 and EUROSEM models. J. Soil Water Conserv. 50 (5), 517-520.

van der Molen, W.H., Torfs, P.J.J.F., de Lima, J.L.M.P., 1995. Water depths at the upper boundary for overland flow on small gradients. J. Hydrol. 171, 93-102.

Veihe, A., Rey, J., Quinton, J.N., Strauss, P., Sancho, F.M., Somarriba, M., 2001. Modelling of event-based soil erosion in Costa Rica, Nicaragua and Mexico: evaluation of the EUROSEM model. Catena 44 (3), 187-203.

Woolhiser, D.A., 1975. Simulation of unsteady overland flow. In: Mahmood, K. Yevjevich, Y. (Eds.), Unsteady Flow in Open Channels, vol. II. Water Resources Publications, Fort Collins, CO, USA, pp. 485-508.

Woolhiser, D.A., Smith, R.E., Goodrich, D.C., 1990. KINEROS, A Kinematic Runoff and Erosion Model: Documentation and User Manual. U.S. Department of Agriculture, Agricultural Research Service, ARS-77.

Yu, B., 2003. A unified framework for water erosion and deposition equations. Soil Sci. Soc. Am. J. 67, 251-257. 